\title{
Pendampingan Kegiatan Lesson Study for Learning Community (LSLC) Guru Matematika MTS-MA-SMK Pondok Pesantren Darussholihin NW Kalijaga Lombok Timur
}

\section{Sripatmi*, Ratih Ayu Apsari, Nourma Pramestie Wulandari, Ulfa Lu'luilmaknun, Nilza Humaira Salsabila}

Pendidikan Matematika, FKIP, Universitas Mataram, Mataram

spatmi@gmail.com

\begin{abstract}
As an effort to develop the teaching profession, Lesson Study for Learning Community (LSLC) emphasizes the importance of collaborative and continuous learning assessment based on the principles of collegiality and mutual learning to build a learning community. Based on discussions with the head of Darussholihin Islamic Boarding School (Ponpes) NW Kalijaga, East Lombok, principals of MTs-SMP, MA-SMA, and Vocational Schools fostered by Ponpes Darussholihin NW Kalijaga, it was revealed that: mathematics is one of the subjects that most students are less interested in. MTs-SMP, MA-SMA, SMK fostered by Ponpes Darussholihin NW Kalijaga, as well as most mathematics teachers still have difficulty planning and implementing learning strategies that can guide students in finding mathematical concepts, principles, and problem solving. To solve these problems, assistance is needed, through LSLC activities for school mathematics teachers at Ponpes Darussholihin NW Kalijaga, in order to resolve problems related to the implementation of mathematics learning. This service activity is carried out by utilizing several methods, namely: lectures, questions and answers, discussions, and providing assistance when mathematics teachers carry out the LSLC steps, including Plan, Do, See, and Re-design activities. Through mentoring activities carried out from September 18 to October 2, 2021, it was concluded that mentoring activities could: i) improve the understanding and skills of Mathematics teachers in schools at Ponpes Darussholihin NW Kalijaga in designing (plan), implementing (do), reflecting (see), and re-design of learning as regulated in the 2013 curriculum; ii) increasing collegiality among mathematics teachers at the Darussholihin Islamic Boarding School's fostered schools, NW Kalijaga.
\end{abstract}

Keywords: assistance; lesson study; learning community

\begin{abstract}
Abstrak
Sebagai usaha pembinaan profesi pendidik, Lesson Study for Learning Community (LSLC) menekankan pentingnya pengkajian pembelajaran secara kolaboratif dan berkesinambungan berlandaskan prinsipprinsip kolegialitas dan mutual learning untuk membangun komunitas belajar. Berdasarkan pembicaraan dengan ketua Pondok Pesantren (Ponpes) Darussholihin NW Kalijaga Lombok Timur, kepala sekolah MTsSMP, MA-SMA, dan SMK binaan Ponpes Darussholihin NW Kalijaga, terungkap bahwa: mata pelajaran matematika merupakan salah satu pelajaran yang kurang diminati oleh sebagian besar siswa MTs-SMP, MA-SMA, SMK binaan Ponpes Darussholihin NW Kalijaga, serta sebagian besar guru matematika masih kesulitan dalam merencanakan dan melaksanakan strategi pembelajaran yang dapat membimbing siswa menemukan konsep, prinsip, dan pemecahan masalah matematika. Untuk mengatasi masalah-masalah
\end{abstract}


tersebut diperlukan pendampingan, melalui kegiatan LSLC pada guru-guru matematika sekolah-sekolah di Ponpes Darussholihin NW Kalijaga, guna mengatasi masalah-masalah berkaitan pelaksanaan pembelajaran matematika. Kegiatan pengabdian ini dilaksanakan dengan memanfaatkan beberapa metode, yaitu: ceramah, tanya jawab, diskusi, dan melakukan pendampingan saat guru-guru matematika melaksanakan tahapan LSLC, meliputi kegiatan Plan, Do, See, dan Re-design. Melalui kegiatan pendampingan yang dilaksanakan dari tanggal 18 September sampai dengan 2 Oktober 2021, disimpulkan bahwa kegiatan pendampingan dapat: i) meningkatkan pemahaman dan keterampilan guru Matematika sekolah-sekolah di Ponpes Darussholihin NW Kalijaga dalam merancang (plan), melaksanakan (do), refleksi (see), dan re-design pembelajaran seperti yang diatur di kurikulum tahun 2013; ii) meningkatkan kolegialitas antar guru-guru matematika sekolah binaan Ponpes Darussholihin NW Kalijaga.

Kata Kunci: pendampingan; lesson study; learning community

\section{PENDAHULUAN}

Pembelajaran adalah proses interaksi peserta didik dengan pendidik dan sumber belajar pada suatu lingkungan belajar. Hal ini sesuai pengertian pembelajaran yang dikemukakan Association of Education and Communication Technology (AECT), pembelajaran adalah proses dengan lingkungan yang secara sengaja dikelola sehingga memungkinkan siswa atau peserta didik turut serta dalam tingkah laku tertentu dalam kondisi - kondisi khusus atau menghasilkan respon terhadap situasi tertentu (AECT, 1986). Selain itu, suatu proses pembelajaran merupakan suatu sistem, yang terdiri atas siswa, guru, bahan ajar, dan lingkungan belajar, dimana seluruh elemen yang ada berinteraksi untuk mencapai tujuan tertentu (Dick, Carey, \& Carey, 2009). Oleh karenanya, pembelajaran dapat berlangsung dengan baik diperlukan perencanaan, meliputi 3 tahap yaitu perancangan, pelaksanaan, serta evaluasi dan refleksi. Perencanaan pembelajaran dilakukan untuk mendapatkan strategi pembelajaran yang tepat agar diperoleh hasil belajar yang optimal sesuai dengan tujuan belajar. Pelaksanaan pembelajaran merupakan implementasi dari perencanaan pembelajaran dan harus dapat diukur atau dievaluasi keberhasilannya. Evaluasi merupakan kegiatan untuk melihat apakah tujuan pembelajaran yang ingin dicapai pada kegiatan pembelajaran tercapai dengan baik, sedangkan refleksi diperlukan untuk memperbaiki rancangan dan pelaksanaan pembelajaran berikutnya. Keberhasilan belajar antara lain ditentukan oleh pemahaman karakteristik isi materi pelajaran, karakteristik pebelajar (peserta didik), dan proses pembelajaran. Karakteristik pebelajar adalah seluruh latar belakang yang dibawa ketika hadir di kelas sebelum pembelajaran dimulai.

Soedijarto (1993) menyatakan bahwa kualitas pendidikan ditentukan oleh pembelajaran di kelas. Tingkat kualitas pembelajaran dapat diperlihatkan oleh tingginya keterlibatan peserta didik dalam pembelajaran, komunikasi antara guru dan peserta didik, serta komunikasi antar peserta didik dalam rangka menemukan konsep-konsep atau menyelesaikan masalah. Salah satu cara yang dapat membantu guru dalam upaya meningkatkan kualitas pembelajaran adalah dengan penerapan model atau strategi pembelajaran yang tidak semata - mata hanya kegiatan guru mengajar, tetapi menitik beratkan pada aktivitas peserta didik, atau bukan guru yang selalu aktif 
memberikan/menjelaskan pelajaran akan tetapi guru yang membantu peserta didik jika memperoleh kesulitan, membimbing diskusi agar mampu membuat kesimpulan yang benar. Keterampilan memilih strategi pembelajaran yang sesuai dengan karakteristik peserta didik dapat ditingkatkan melalui kegiatan diskusi secara periodik dan rutin dengan teman sejawat, serta pendampingan dari tenaga yang berkompeten dalam bidangnya, salah satunya melalui kegiatan Lesson Study for Learning Community (LSLC). LSLC adalah penyempurnaan dari lesson study, yaitu suatu model pembinaan profesi guru melalui pengkajian pembelajaran secara kolaboratif dengan sistem siklus dan berkelanjutan berlandaskan prinsip-prinsip kolegalitas dan mutual learning untuk membangun learning community (Subadi, 2013).

Penyempurnaan kegiatan Lesson Study (LS) menjadi LSLC yaitu dengan menambahkan aktivitas re-design. Re-design merupakan aktivitas yang dilakukan setelah aktivitas see/refleksi, yaitu kegiatan memperbaiki lesson plan yang dirancang di awal siklus sesuai hasil refleksi yang dilaksanakan setelah kegiatan do (pelaksanaan pembelajaran). Hasil re-design ini diimplementasikan untuk pembelajaran konsep atau prinsip yang sama di kelas paralel atau untuk penyusunan lesson plan konsep/prinsip selanjutnya. Sebagai usaha pembinaan profesi pendidik, LSLC menekankan pentingnya pengkajian pembelajaran secara kolaboratif dan berkesinambungan untuk membangun komunitas belajar (Wahyuni, 2020). Hal ini sesuai dengan hasil pengabdian masyarakat yang telah kami laksanakan tahun 2017 di SMPN 13 Mataram, tahun 2019 di Mts Darul Qur'an Bengkel, dan tahun 2020 di MGMP kecamatan Sandubaya Mataram. Kegiatan sosialisasi dan implementasi Lesson Study berbasis sekolah di SMPN 13 Mataram, dapat menambah pemahaman guru-guru dalam menyiapkan perangkat pembelajaran (RPP, Media, dan alat penilaian) yang praktis, mudah dilaksanakan, serta melibatkan siswa aktif saat pembelajaran. Kegiatan Pelatihan Penyusunan Perangkat Pembelajaran Matematika melalui kegiatan Lesson Study di Mts Darul Qur'an Bengkel, guru-guru dapat merancang perangkat pembelajaran dan melaksanakan pembelajaran di kelas yang melibatkan siswa aktif dalam pembelajaran. Kegiatan Implementasi Lesson Study for Learning Community (LSLC) MGMP Matematika SMP Kecamatan Sandubaya Mataram, menambah pemahaman dan keterampilan peserta dalam hal merancang (plan), melaksanakan (do), refleksi (see), dan re-design pembelajaran, serta peningkatan kolegialitas antar guru-guru matematika SMP yang tergabung dalam pokja Cakranegara-Sandubaya Mataram dalam membelajarkan peserta didik melalui tukar pengalaman (Sripatmi et al., 2020, 2021).

Berdasarkan pembicaraan dengan ketua Pondok Pesantren (Ponpes) Darussholihin NW Kalijaga Lombok Timur, kepala sekolah MTs-SMP, MA-SMA, dan SMK binaan Ponpes Darussholihin NW Kalijaga, terungkap bahwa: i) mata pelajaran Matematika merupakan salah satu pelajaran yang kurang diminati oleh sebagian besar siswa MTsSMP, MA-SMA, dan SMK binaan Ponpes Darussholihin NW Kalijaga, oleh karenanya sebagian besar siswa kurang terlibat dalam pembelajaran matematika, ii) memiliki 27 
guru matematika dan sebagian besar guru matematika masih kesulitan dalam merencanakan dan melaksanakan strategi pembelajaran yang dapat membimbing siswa menemukan konsep, prinsip, dan pemecahan masalah matematika, iii) sebagian besar guru matematika masih merasa kesulitan merancang skenario pembelajaran satu halaman yang dapat melibatkan siswa belajar aktif dan menyenangkan. Untuk mengatasi masalah-masalah tersebut diperlukan kegiatan pendampingan, melalui kegiatan LSLC. Fakultas Keguruan dan Ilmu Pendidikan Universitas Mataram (FKIP Unram) mulai tahun 2009 sebagian besar tenaga pendidiknya mempraktekan Lesson Study (LS) di kegiatan perkuliahan dan melaksanakan pendampingan implementasi LS di beberapa sekolah mitra, dipandang perlu melaksanakan pendampingan kegiatan LSLC pada guru-guru matematika sekolah-sekolah di Ponpes Darussholihin NW Kalijaga, guna mengatasi masalah-masalah berkaitan pelaksanaan pembelajaran matematika. Beberapa kegiatan lesson study yang dilakukan sebelumnya juga telah menunjukkan dapat membantu guru untuk meningkatkan kualitas pembelajaran matematika (Fauziah \& Putri, 2021; Lewis, 2016; Nuraida \& Putri, 2019; Setyaningsih, 2018).

Memperhatikan uraian di atas, dipandang perlu dilaksanakan pengabdian kepada masyarakat di Ponpes Darussholihin NW Kalijaga Lombok Timur dengan topik "Pendampingan Kegiatan Lesson Study for Learning Community (LSLC) Guru Matematika SMP/MTs-MA-SMK Pondok Pesantren Darussholihin NW Kalijaga Lombok Timur". Kegiatan ini bertujuan untuk: i) meningkatkan pemahaman guru Matematika SMP/MTs-MA-SMK Pondok Pesantren Darussholihin NW Kalijaga Lombok Timur, berkaitan dengan pengertian dan fungsi, serta melaksanakan LSLC yang meliputi kegiatan merancang (plan), melaksanakan (do), refleksi (see), dan re-design; ii) meningkatkan kolegialitas antar guru-guru matematika SMP/MTs-MA-SMK Pondok Pesantren Darussholihin NW Kalijaga Lombok Timur dalam membelajarkan peserta didik melalui tukar pengalaman melalui kegiatan LSLC.

\section{METODE PELAKSANAAN}

Subjek kegiatan pengabdian ini adalah 27 guru matematika SMP/MTs-MA-SMK Pondok Pesantren Darussholihin NW Kalijaga Lombok Timur. Tempat pengabdian di SMP NW Kalijaga, saat pelaksanaan kegiatan sosialisasi LCLC dan pendampingan plan/perencanaan, serta di MA DH NW Kalijaga saat pendampingan do/pelaksanaan pembelajaran dan see/refleksi.

Untuk mencapai tujuan yang dirumuskan dalam kegiatan pengabdian kepada masyarakat ini tercapai digunakan beberapa metode, yaitu: ceramah, tanya jawab, diskusi, dan pendampingan saat guru-guru matematika melaksanakan tahapan LSLC, meliputi kegiatan Plan, Do, See, dan Re-design, yang dilaksanakan 1 siklus. Dengan rincian masing-masing metode sebagai berikut: 
1) Metode ceramah digunakan saat sosialisasi LSLC meliputi pengertian, fungsi, dan tahapan kegiatan LSLC.

2) Metode tanya jawab, dimaksudkan untuk memberikan kesempatan kepada peserta pengabdian terkait dengan materi yang telah disampaikan serta permasalahan lain yang dihadapi guru dalam menyiapkan dan melaksanakan pembelajaran daring.

3) Metode diskusi, digunakan saat peserta pengabdian melaksanakan kegiatan plan dan see pada saat implementasi LSLC.

4) Metode pendampingan, digunakan tim pengabdian saat merancang (plan), melaksanakan (do), refleksi (see), dan re-design pembelajaran.

\section{HASIL DAN PEMBAHASAN}

Kegiatan pengabdian masyarakat pendampingan kegiatan Lesson Study for Learning Community (LSLC) Guru Matematika SMP/MTs-MA-SMK Pondok Pesantren Darussholihin NW Kalijaga Lombok Timur dilaksanakan dari tanggal 18 September sampai dengan tanggal 02 Oktober 2021. Sebelum pelaksanaan pendampingan beberapa guru matematika dan kepala sekolah mengikuti kegiatan workshop LSLC secara daring, yang dilaksanakan oleh tim LSLC FKIP Universitas Mataram pada tanggal 12 - 14 Agustus 2021 yang dihadiri sekitar 250 peserta berasal dari berbagai daerah dan perguruan tinggi di Indonesia.

Kegiatan pendampingan diawali dengan sosialisasi LSLC, meliputi pengertian, fungsi, dan tahapan LSLC secara garis besar. Kegiatan ini diikuti oleh sebagian guru SD/MiSMP/MTs-SMA/MA-SMK ponpes Darussholihin NW Kalijaga, bertempat di SMP NW Kalijaga. Kegiatan sosialisasi diawali dengan sambutan sekretaris ponpes Darussholihin, sebagai ungkapan terima kasih atas kesediaan tim LSLC FKIP Universitas Mataram yang berkenan melaksanakan pendampingan kegiatan LSLC guru-guru sekolah di bawah naungan ponpes Darussholihin NW Kalijaga. Dari sambutan tersebut, diperoleh data bahwa ponpes telah berdiri sejak tahun 1967 yang menaungi 24 lembaga sekolah dari taman kanak-kanak sampai sekolah lanjutan atas, memiliki tenaga pengajar 400 orang, dan peserta didiknya berasal dari berbagai daerah di NTB dan Jawa. Peserta didik yang berasal dari luar Lombok Timur berdomisili di pondok. Kegiatan sosialisasi dilanjutkan sambutan dan penjelasan pengertian, fungsi, dan tahapan LSLC secara singkat oleh salah satu tim LSLC FKIP Universitas Mataram. Dan kegiatan sosialisasi diakhiri do'a yang dipimpin oleh salah satu guru ponpes. Berikut foto-foto kegiatan sosialisasi LSLC. 

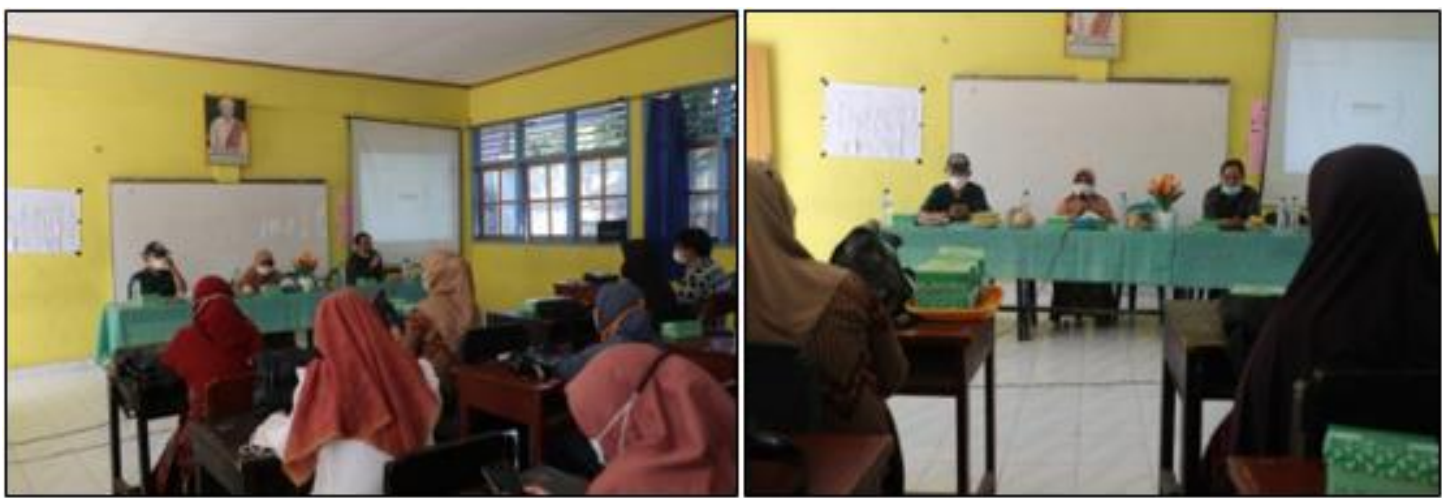

Gambar 1. Saat sekretaris ponpes memberikan sambutan dan salah satu tim LSLC memberikan sambutan dan penjelasan singkat LSLC

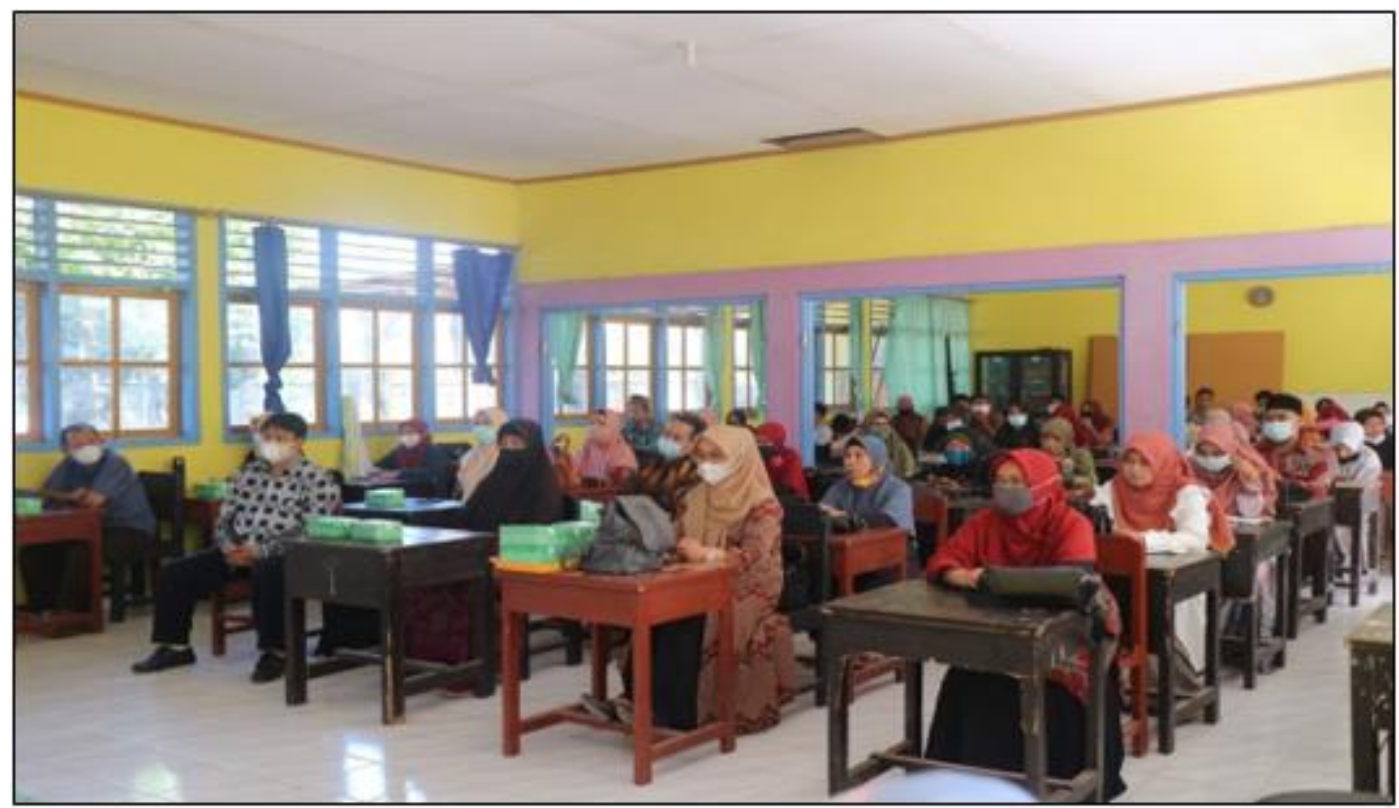

Gambar 2. Peserta sosialisasi LSLC

Kegiatan dilanjutkan pendampingan secara terpisah untuk masing-masing guru mapel Bahasa Inggris, Kimia, Matematika, dan Guru Sekolah Dasar oleh masing-masing tim bidang studi.

Kegiatan pendampingan LSLC guru matematika diawali dengan penjelasan secara rinci aktivitas yang dilaksanakan pada setiap tahapan LSLC, meliputi: i) apa dan bagaimana melaksanakan kegiatan plan khususnya merancang chapter dan lesson design; ii) teknik observasi; iii) refleksi. Peserta nampak tekun mendengarkan penjelasan tim, terlihat saat sesi tanya jawab beberapa peserta mengajukan pertanyaan berkaitan teknik penyusunan chapter dan lesson design, apa saja yang harus dilengkapi/dilampirkan di lesson design, serta hal-hal apa saja yang boleh dan tidak boleh dilakukan saat kegiatan pengamatan/observasi dan refleksi. 
Setelah berakhir kegiatan tanya jawab, dilanjutkan kegiatan plan/perencanaan. Bertindak sebagai guru model adalah Ibu Sartika Farhiyan, guru matematika MA DH NW Kalijaga. Untuk kegiatan open lesson bertepatan dengan materi Matriks, sub materi Determinan. Kegiatan plan diawali dengan diskusi pembuatan chapter design dan lesson design dipimpin langsung oleh guru model, dengan tahapan: i) guru model menyampaikan tujuan pembelajaran, metode dan media pembelajaran yang akan dimanfaatkan saat pembelajaran; ii) guru lain memberikan masukan; iii) tim memberikan arahan urutan pencapaian tujuan pembelajaran. Karena keterbatasan waktu, kegiatan diskusi plan dilanjutkan secara daring melalui grup WA, dilaksanakan pada tanggal 20 - 30 September 2021. Melalui diskusi via grup WA dihasilkan perangkat pembelajaran, meliputi chapter design, lesson design, rencana pelaksanaan pembelajaran (RPP), dan lembar kerja peserta didik (LKPD). Berikut foto-foto kegiatan plan.

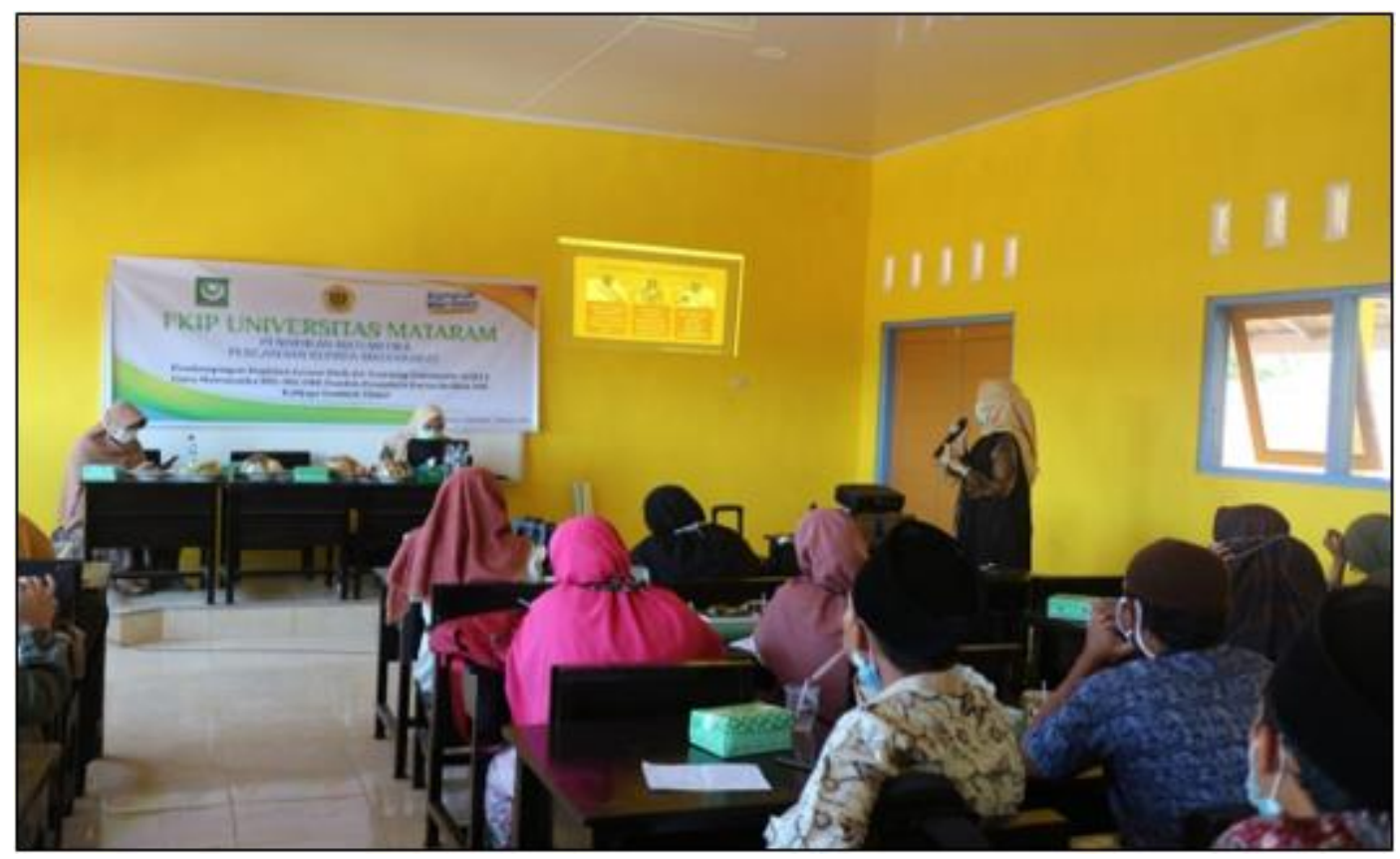

Gambar 3. Saat penjelasan teknik penyusunan chapter dan lesson design 


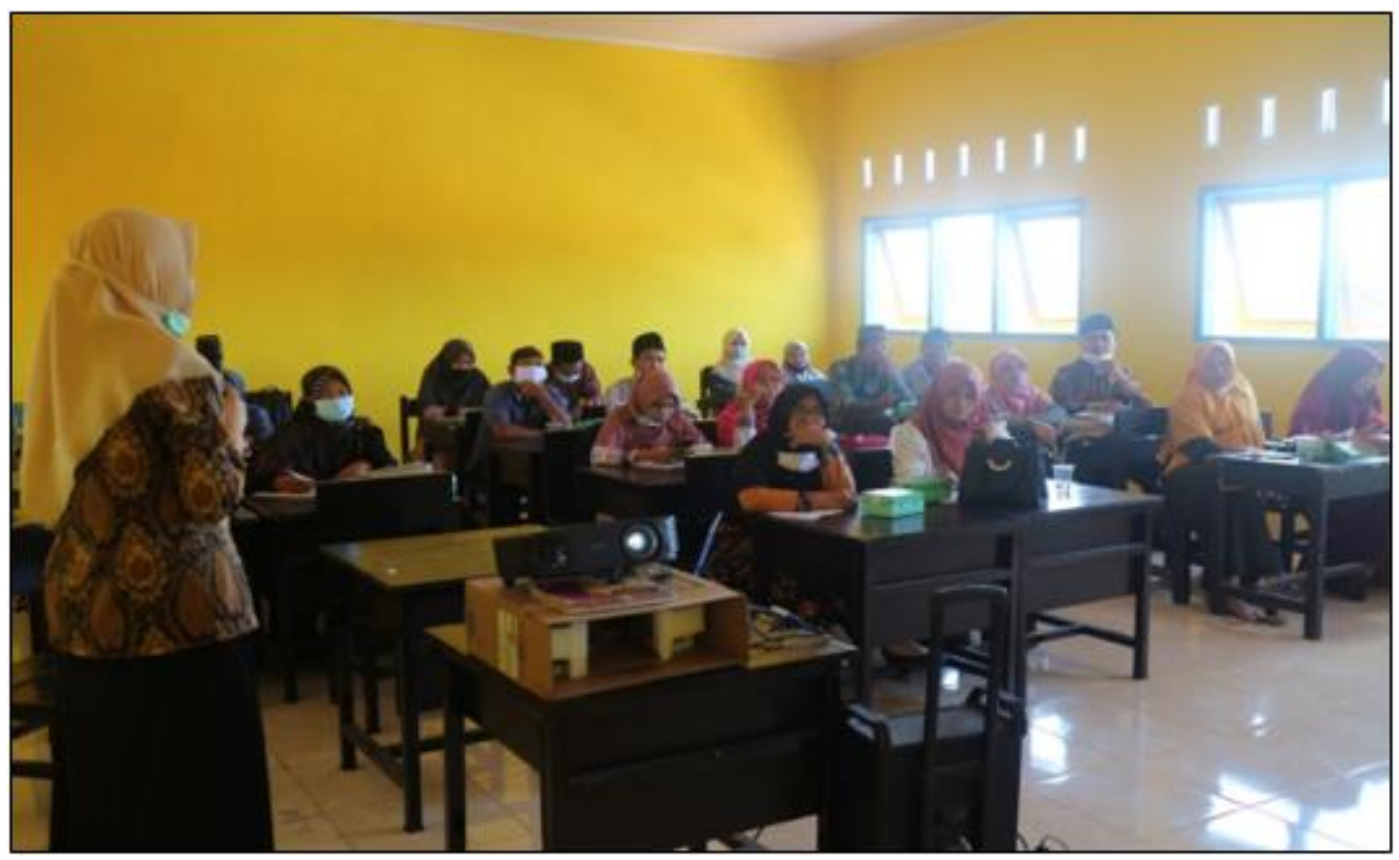

Gambar 4. Saat penjelasan teknik observasi

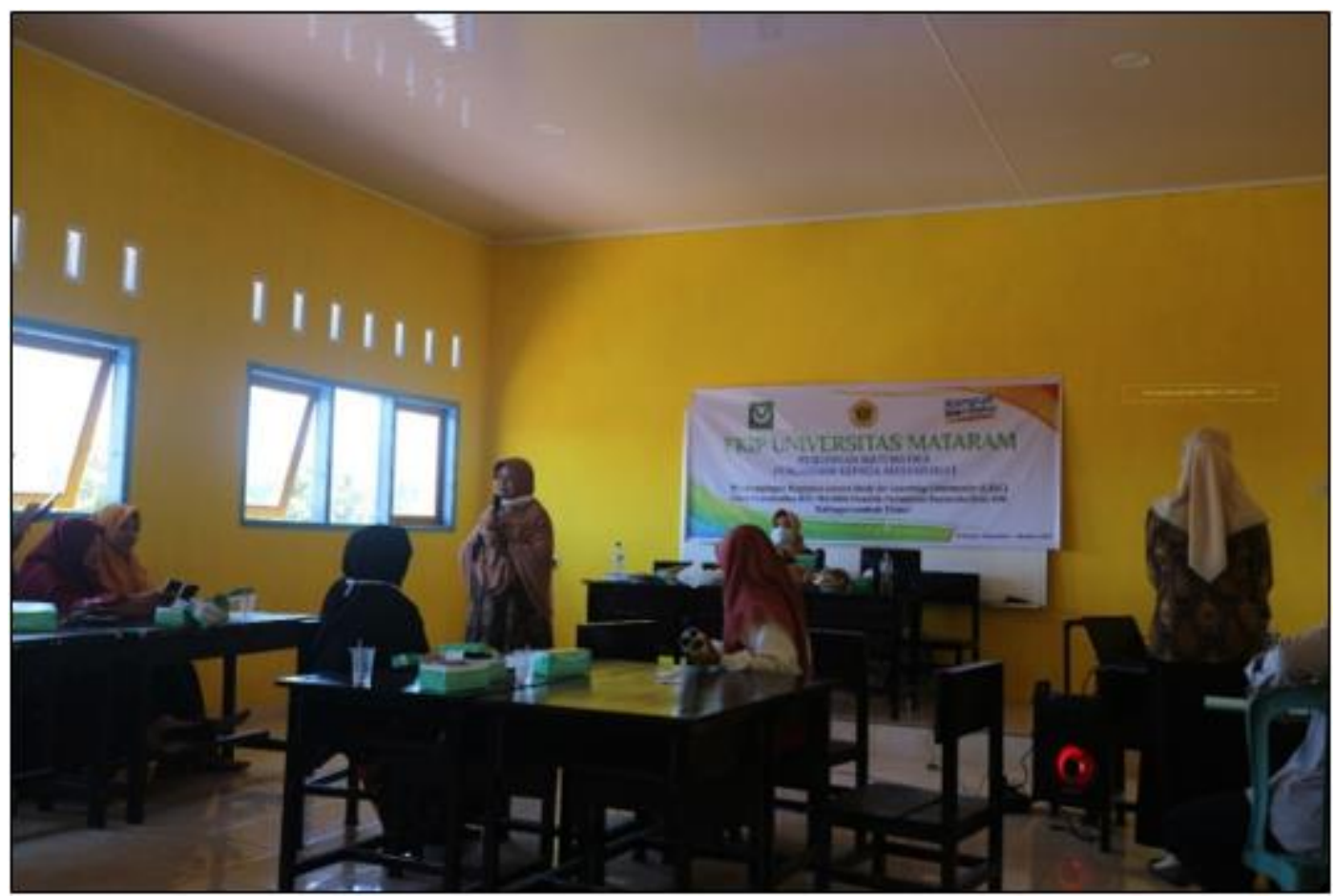

Gambar 5. Saat penjelasan rambu-rambu pelaksanaan refleksi 


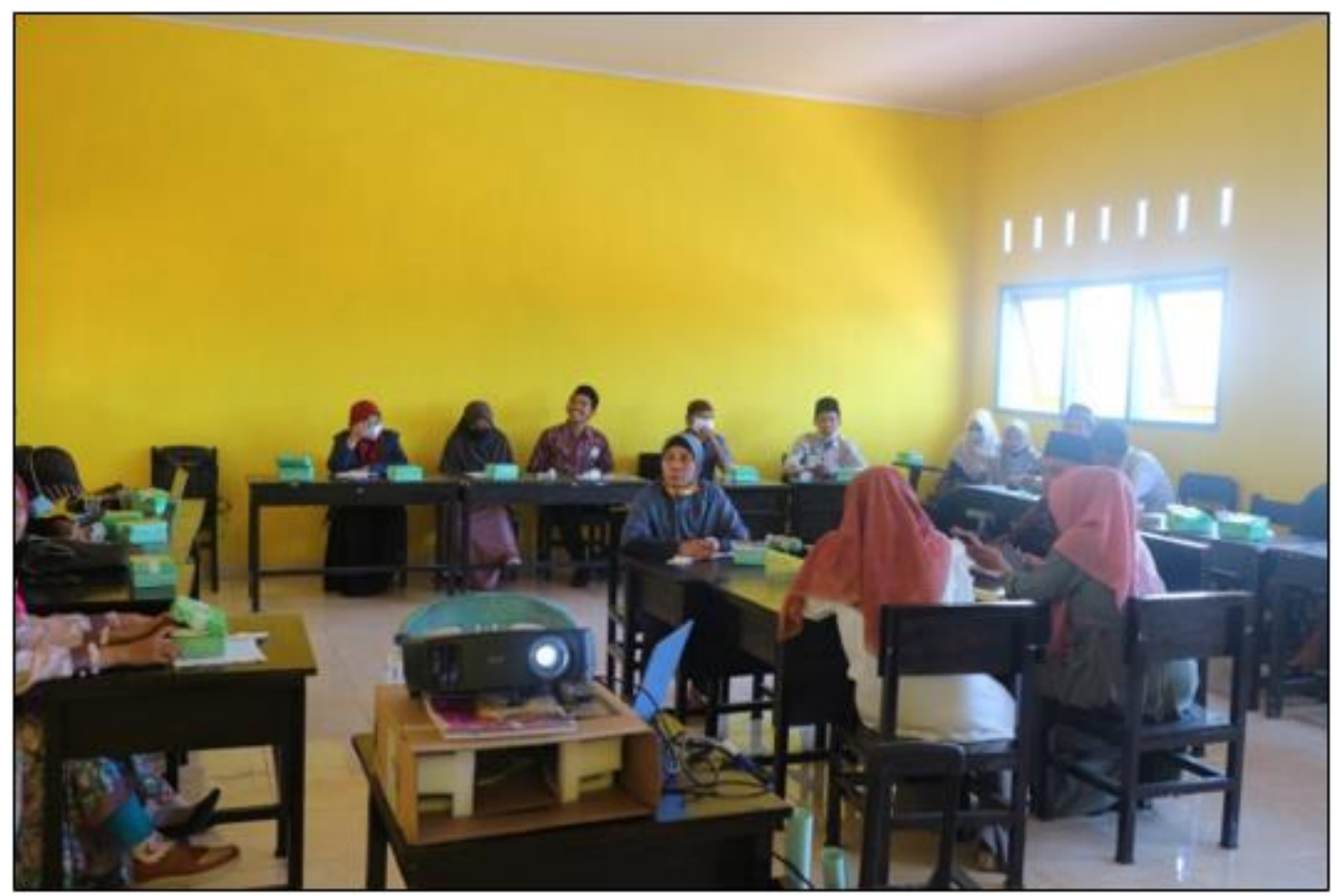

Gambar 6. Guru model mulai memimpin diskusi menyusun chapter dan lesson design

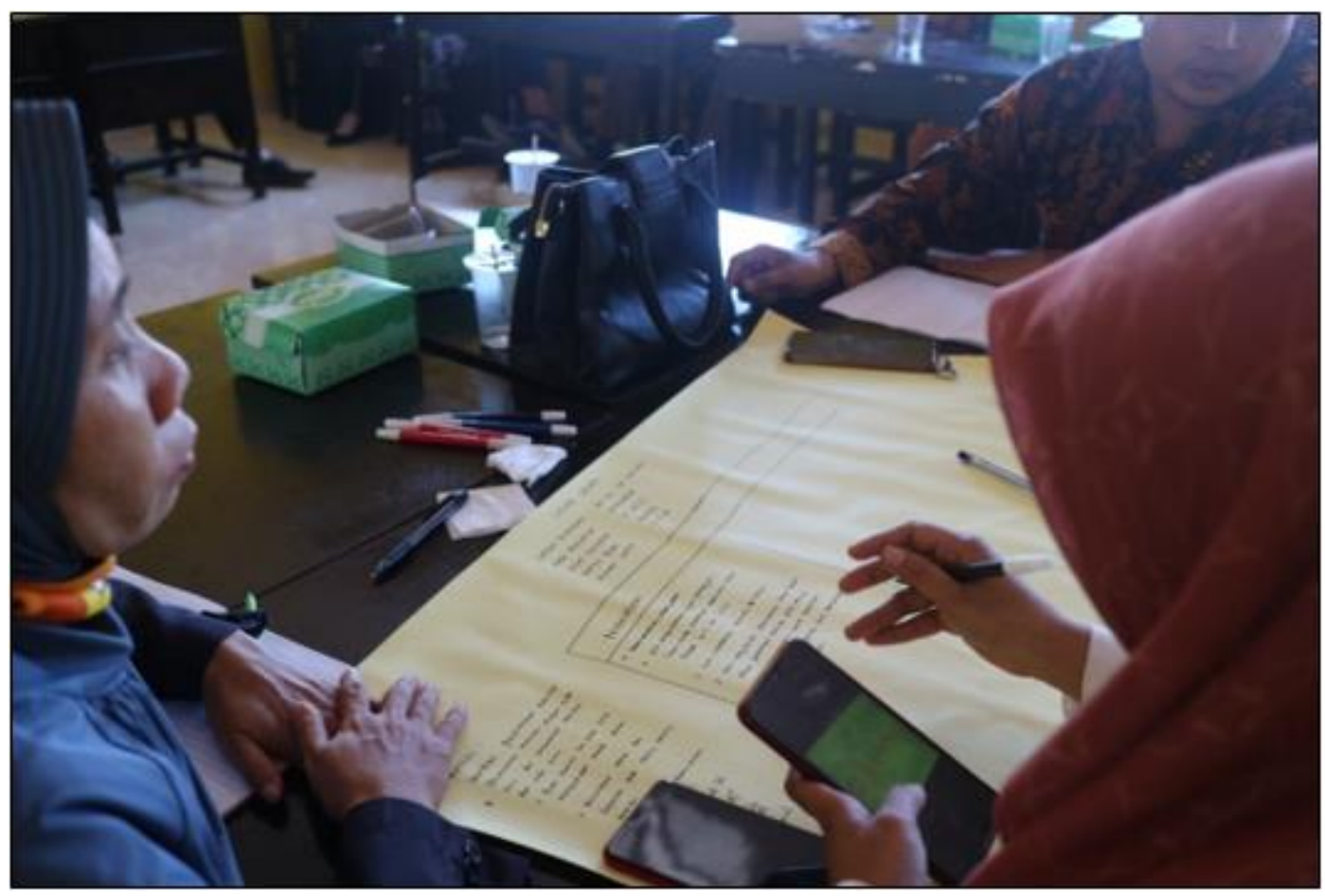

Gambar 7. Draf lesson design 
Kegiatan pendampingan pelaksanaan pembelajaran ( $d o$ ) dan refleksi (see) dilaksanakan pada tanggal 02 Oktober 2021 di MA DH NW Kalijaga. Pembelajaran dilaksanakan 90 menit dari pukul 10.00 - 11.30 WITA. Pembelajaran terlaksana dengan baik, sebagian besar siswa tampak bersemangat, memperhatikan ulasan guru, menjawab saat guru bertanya, serius saat diskusi dan mampu menuliskan dan menjelaskan hasil diskusinya. Seperti nampak pada foto-foto kegiatan pembelajaran berikut:

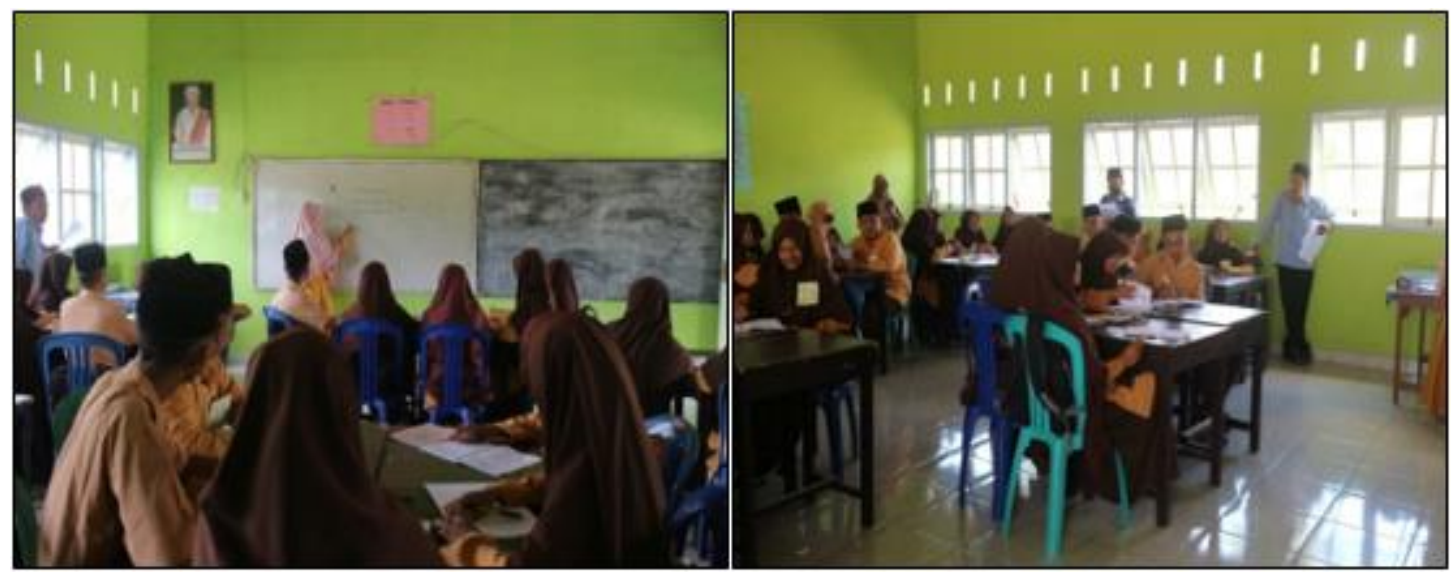

Gambar 8. Memperhatikan ulasan guru

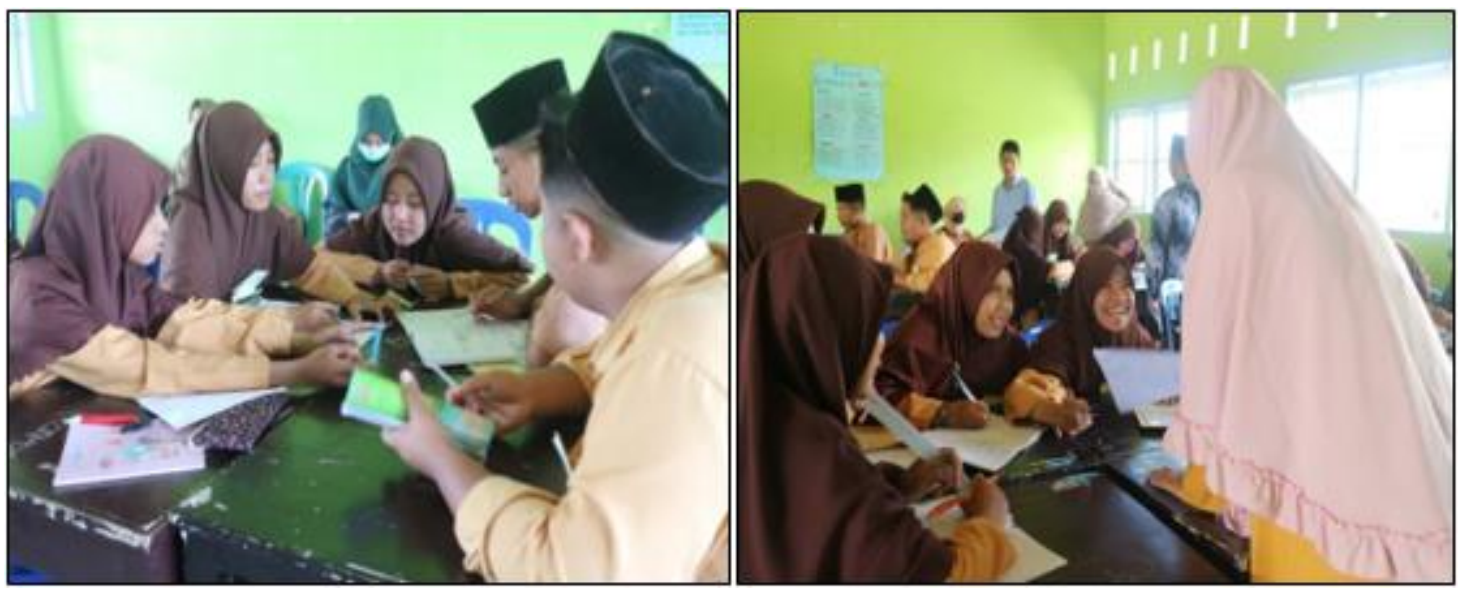

Gambar 9. Saat siswa berdiskusi menyelesaikan LKPD 


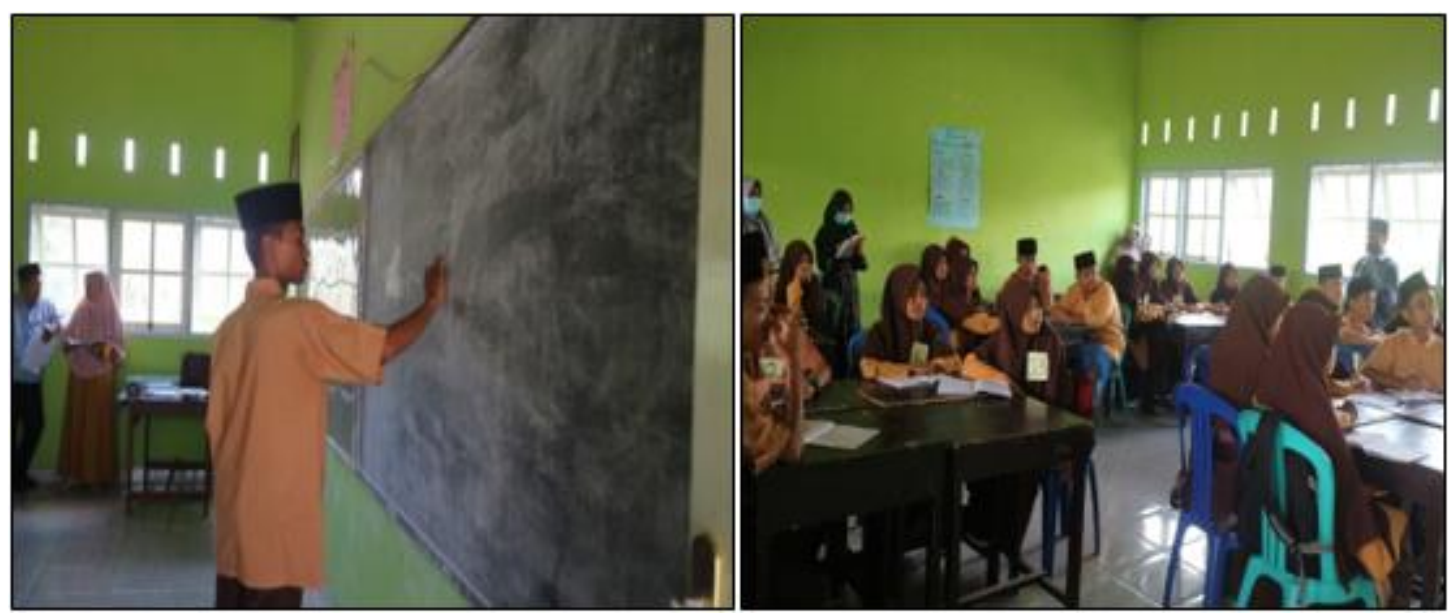

Gambar 10. Salah satu siswa presentasi dan siswa lainnya memperhatikan

Rangkaian terakhir pendampingan LSLC adalah kegiatan refleksi/see, diikuti oleh seluruh guru matematika SMP/MTs-MA-SMK ponpes Darussholihin yang hadir sebagai observer saat pembelajaran/do, Bapak Musaitir Fahmi, SHI selaku kepala MA DH NW Kalijaga, serta empat tim LSLC prodi pendidikan Matematika FKIP Universitas Mataram. Bertindak sebagai moderator pada refleksi Bapak Ahmad Zaenuddin, salah satu guru matematika MA DH NW Kalijaga. Menurut rambu-rambu refleksi yang bertindak sebagai moderator adalah kepala MA, berhubung saat pembelajaran kepala MA ada kesibukan lain dan tidak dapat bergabung menjadi menjadi observer sehingga tidak dapat menjadi moderator.

Kegiatan refleksi dibuka oleh moderator dan memperkenalkan nama-nama peserta refleksi dan menyampaikan secara singkat tahapan dan aturan kegiatan refleksi. Selanjutnya moderator mempersilahkan guru model untuk menyampaikan perasaan, pengalamannya sebagai guru model, hal-hal yang pelaksanaannya kurang sesuai dengan yang direncanakan, serta perkiraan keberhasilan dari pembelajaran yang dilaksanakan.

Beberapa hal yang disampaikan oleh guru model adalah: i) di awal pelaksanaan pembelajaran agak grogi karena banyak yang mengawasi pembelajarannya, tetapi setelah melihat siswa lebih bersemangat memperhatikan arahannya rasa grogi hilang; ii) menurut pantauannya setiap siswa melaksanakan diskusi LKPD dengan anggota kelompoknya; iii) ada siswa yang biasanya tidak berkenan tampil kedepan untuk menuliskan jawaban, berkenan tampil presentasi; iv) sekitar $75 \%$ siswanya telah mencapai tujuan pembelajaran yang ditetapkan, yaitu dapat menentukan determinan matriks persegi berordo 2 dan 3 serta menentukan minor dan kofaktor suatu matriks.

Kegiatan refleksi dilanjutkan dengan beberapa observer menyampaikan hasil pengamatan aktivitas belajar siswa. Berikut temuan yang disampaikan oleh beberapa observer, yaitu: i) siswa nomor 3 dan nomor 14 masih kurang berpartisipasi, ketika guru 
datang mereka belum siap untuk belajar, siswa nomor 14 kurang konsentrasi, sering menengok ke kiri untuk melihat pekerjaan teman dan terlihat tidak bisa memecahkan soal sendiri; ii) saat guru membuka pembelajaran siswa nomor 19 diam saja dan menghadap jendela, dan saat kegiatan diskusi kelompok hanya mengobrol dan tertawa dengan siswa 24; iii) siswa nomor 13 dari kegiatan awal sampai akhir bukunya tidak dibuka untuk menulis pelajaran, dan tidak ikut diskusi, siswa nomor 7 dan 17 juga tidak ikut diskusi kelompok; iv) semua anggota kelompok 6 dan 4 terlihat aktif dalam diskusi kelompok; v) di awal kegiatan diskusi kelompok siswa no 28 nampak belum siap tetapi untuk selanjutnya dapat mengikuti kegiatan diskusi dan nampak memperhatikan presentasi hasil diskusi yang disampaikan perwakilan kelompok lain; vi) siswa nomor 20 yang merupakan anggota kelompok 4 kurang percaya diri dalam menyampaikan pendapatnya. Tanggapan guru model atas hasil pengamatan oleh observer, sebagai berikut: i) siswa nomor 19 biasanya duduknya di pojok kanan belakang, ketika pembelajaran suka tertidur, sehingga tidak dapat memahami konsep dan prinsip materi pembelajaran dan slow respon; ii) siswa nomor 7 pada kegiatan pembelajaran biasa duduk di belakang, pendiam, dan saat waktu istirahat tetap di kelas duduk di bangkunya, dan jarang berbincang meskipun diajak ngomong; iii) siswa nomor 17 dan 20 memang kurang percaya diri, meskipun meskipun telah selesai mengerjakan soal dan benar; iv) secara umum merasa senang karena siswanya bersemangat dan cepat merespon, berbeda dengan situasi pembelajaran sebelumnya mereka lebih sering curhat, tidur, izin keluar. Kegiatan refleksi diakhiri dengan arahan dan simpulan kegiatan pendampingan LSLC oleh kepala sekolah, dan masukan dari salah satu tim LSLC pendidikan matematika FKIP Universitas Mataram. Berikut foto-foto kegiatan refleksi.

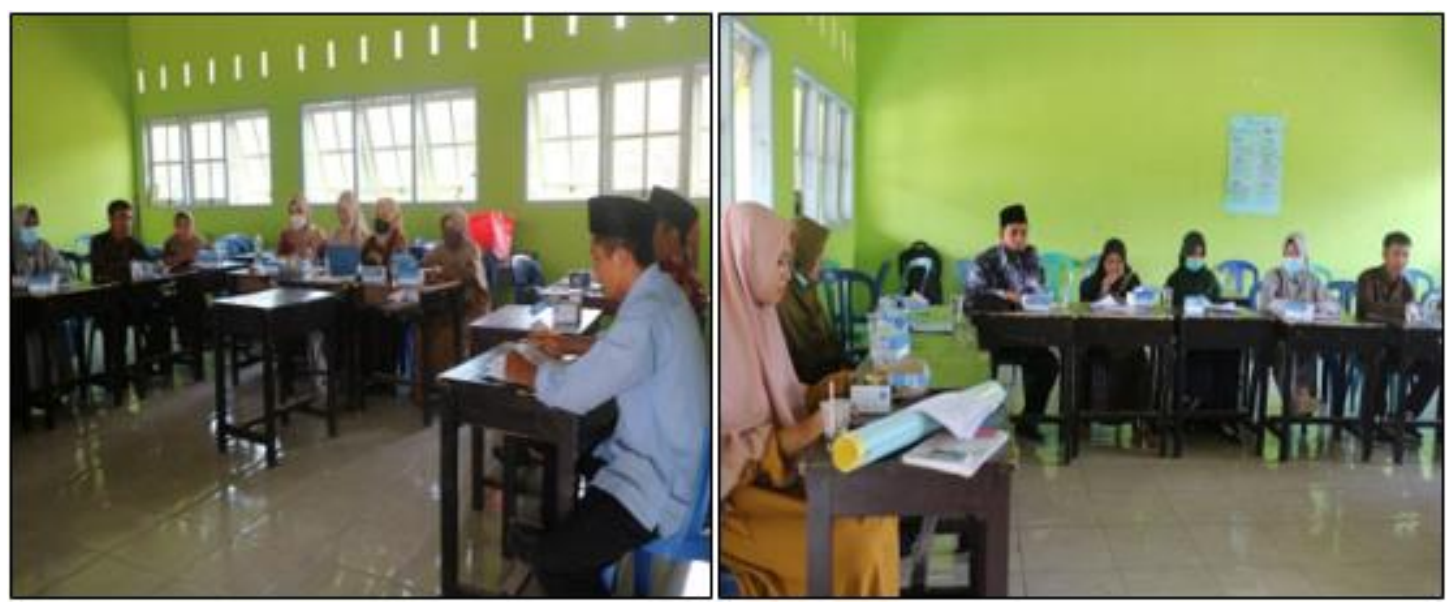

Gambar 11. Moderator membuka kegiatan refleksi dan guru model menyampaikan pengalamannya 


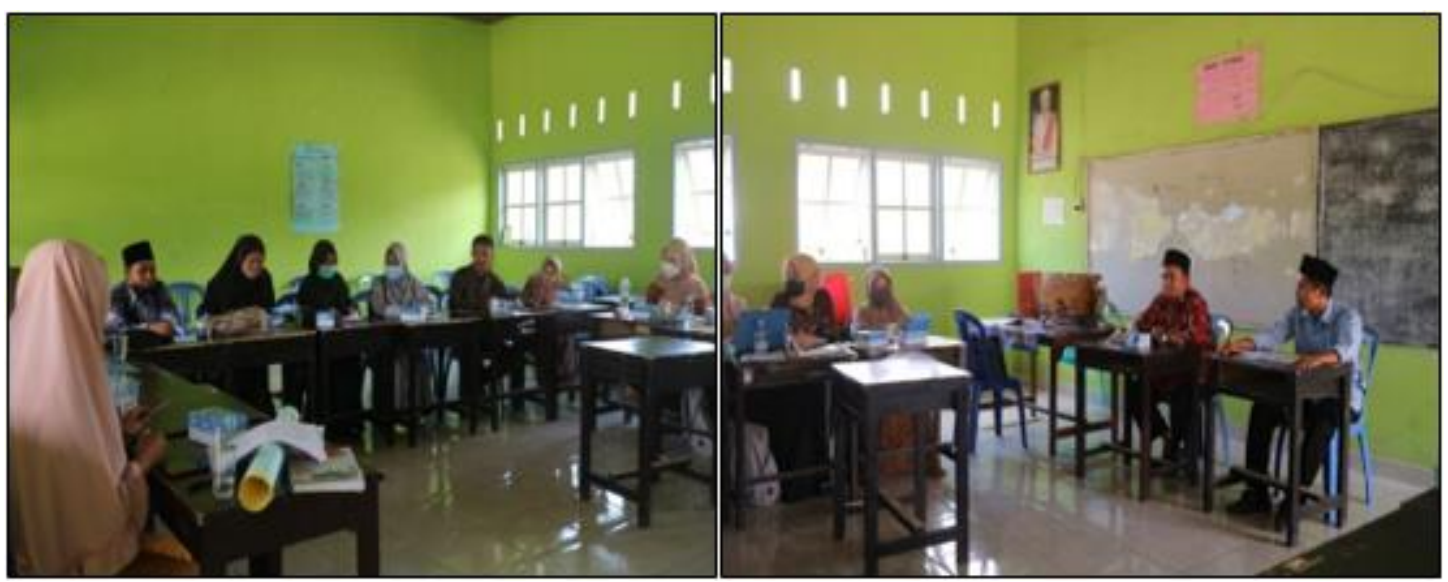

Gambar 12. Observer menyampaikan hasil pengamatannya dan kepala sekolah memberikan arahan dan simpulan kegiatan LSLC

\section{SIMPULAN}

Berdasarkan uraian di atas, dapat disimpulkan bahwa melalui pendampingan kegiatan LSLC dapat: i) meningkatkan pemahaman guru Matematika SMP/MTs-MA-SMK Pondok Pesantren Darussholihin NW Kalijaga Lombok Timur, berkaitan dengan pengertian dan fungsi, serta melaksanakan LSLC yang meliputi kegiatan merancang (plan), melaksanakan (do), refleksi (see), dan re-design; ii) meningkatkan kolegialitas antar guru-guru matematika SMP/MTs-MA-SMK Pondok Pesantren Darussholihin NW Kalijaga Lombok Timur dalam membelajarkan peserta didik melalui tukar pengalaman melalui kegiatan LSLC; iii) terciptanya upaya pemenuhan hak belajar setiap peserta didik di MA Pondok Pesantren Darussholihin NW Kalijaga Lombok Timur.

Berdasarkan hasil kegiatan pendampingan disarankan agar ponpes Darussholihin NW Kalijaga Lombok Timur, secara rutin memfasilitasi guru-guru di sekolah binaannya dapat melaksanakan kegiatan LSLC sesuai rumpun mata pelajaran yang diampu agar pemahaman dan keterampilan melaksanakan kegiatan LSLC meningkat, kolegialitas antar guru dan pemenuhan hak belajar siswa lebih baik.

\section{UCAPAN TERIMA KASIH}

Atas terlaksananya kegiatan ini tim sampaikan terimakasih atas dukungan pendanaan PNBP tahun 2021 dari FKIP Universitas Mataram dengan nomor kontrak: 1915/UN18.L1/PP/2021. Serta terimakasih kepada pihak ponpes Darussholihin NW Kalijaga Lombok Timur atas sarana dan fasilitas yang telah diberikan untuk terlaksananya kegiatan pengabdian masyarakat tim LSLC program studi Pendidikan Matematika FKIP Universitas Mataram. 


\section{REFERENSI}

AECT. (1986). Instructional Technology: The Definition and Domains of The Field (Diterjemahkan oleh Yusufhadi, dkk). Jakarta: IPTPI dan LPTK.

Dick, W., Carey, L., \& Carey, J. O. (2009). The Systematic Design of Instruction (Seventh Ed). Pearson Education, Inc.

Fauziah, A., \& Putri, R. I. I. (2021). Pembelajaran PMRI melalui Lesson Study. Palembang: Bening Media Publishing.

Lewis, C. (2016). How Does Lesson Study Improve Mathematics Instruction? ZDM, 48(4), 571580.

Nuraida, E. M., \& Putri, R. I. I. (2019). Implementasi Lesson Study dalam Pembelajaran Matematika Materi Perkalian dan Pembagian Bilangan Bulat Peserta Didik Kelas VII. Seminar Nasional Pendidikan Matematika Ahmad Dahlan, 6.

Setyaningsih, L. (2018). Pelaksanaan Lesson Study for Learning Community di MGMP Matematika SMP Kota Malang Tahun 2017. Pi: Mathematics Education Journal, 1(2).

Soedijarto. (1993). Memantapkan Sistem Pendidikan Nasional. Grasindo.

Sripatmi, Apsari, R. A., Wulandari, N.P. Lu'luilmaknun, U., \& Salsabila, N. H. (2021). Implementasi Lesson Study for Learning Community MGMP Matematika SMP Kecamatan Sandubaya Mataram. Jurnal Pendidikan Dan Pengabdian Masyarakat, 4(3).

Sripatmi, Apsari, R. A., Wulandari, N. P., Lu'luilmaknun, U., \& Salsabila, N. H. (2020). Pelatihan Komunikasi Digital pada Implementasi Lesson Study Selama Pandemi COVID-19 bagi MGMP Matematika SMP Kecamatan Sandubaya. Prosiding Semnaskom 2020 Prodi Ilmu Komunikasi Universitas Mataram.

Subadi, T. (2013). Lesson Study sebagai Inovasi Pendidikan. Solo: Kafilah Publishing.

Wahyuni, R. (2020). Efektivitas Implementasi Lesson Study Learning Community dalam Meningkatkan Kualitas Pembelajaran. Equity in Education Journal, 2(1), 11-18. 